Check for updates

Cite this: RSC Adv., 2019, 9, 14599

\title{
Fabrication of a biconnected structure PVB porous heddle via thermally induced phase separation
}

Received 31st January 2019

Accepted 8th April 2019

DOI: 10.1039/c9ra00836e

rsc.li/rsc-advances
Yunying Luo, ${ }^{\text {a }}$ Yangyang $\mathrm{Xu}{ }^{\text {a }}$ Feng Wang, ${ }^{\text {ab }}$ Chengcai Li, ${ }^{\text {a }}$ Jieqi Wang, ${ }^{a}$ Mengtian Jin, ${ }^{c}$ Hailin Zhu (D) *ab and Yuhai Guo (D) *a

Herein, a porous heddle of poly(vinyl butyral) (PVB) was successfully prepared by thermally induced phase separation with PEG400. A phase diagram of PVB was presented, and the effects of various parameters, such as polymer concentration, extrusion temperature, quenching temperature and take-up speed, on the morphology and properties of the PVB porous heddle were investigated. The pore size and porosity of the heddle increase as the extrusion temperature increases. Furthermore, upon increasing the quenching temperature during the TIPS process, the pore size and mechanical properties decrease, whereas porosity increases. In addition, due to the substantially unchanged crystallinity of the PVB heddle, the tensile strength increases since porosity decreases with the increasing take-up speed. The porosity of the prepared PVB porous heddle reached up to $74.63 \%$ when the PVB concentration, the quenching temperature and the extrusion temperature were $20 \mathrm{wt} \%, 0{ }^{\circ} \mathrm{C}$ and $170{ }^{\circ} \mathrm{C}$, respectively. Thus, this porous heddle exhibiting a biconnected structure and significant mechanical properties is promising in the field of porous carrier materials.

\section{Introduction}

Thermally induced phase separation (TIPS) is a useful process to fabricate microporous polymer membranes with diverse morphologies. Typically, the TIPS process involves heating a polymer/diluent mixture at high temperatures to prepare a homogeneous solution and then cooling the solution to low temperatures for phase separation..$^{1,2}$ The selected diluent is closely related to the phase separation behaviors, that is, liquidliquid (L-L) and solid-liquid (S-L) phase separation. Compared with non-solution phase separation (NIPS) methods, the TIPS process is not only simple but also enables facile control of the membrane structures because it has fewer influencing factors such as diluent, cooling rate, polymer concentration, and additives. This method can be used to form porous materials with narrow pore-size distributions, higher strength, elongation of breakage and porosity, and pliability with much better performance when compared with materials produced via the NIPS method. ${ }^{3-5}$ Hence, many researchers have paid attention to the study of forming porous materials by TIPS. ${ }^{6-10}$

Poly(vinyl butyral) (PVB) is prepared by reacting polyvinyl alcohol (PVA) with butyraldehyde in an acidic medium. Substantial amounts of unreacted vinyl alcohol units typically

\footnotetext{
a'hejiang Provincial Key Laboratory of Fiber Materials and Manufacturing Technology, Zhejiang Sci-Tech University, Hangzhou, 310018, China. E-mail: gyh@ zstu.edu.cn; zhhailin@163.com

${ }^{b}$ Zhejiang Kertice Hi-tech Fluor-material Co. Ltd, Wuxing District, Huzhou, 31300o, China

${ }^{c}$ China Textile Academy Ltd, Chaoyang District, Beijing, 100025, China
}

remain in the chain; ${ }^{11}$ PVB is regarded as a random copolymer of vinyl butyral and vinyl alcohol units. The vinyl alcohol unit is polar and hydrophilic, and the vinyl butyral unit is hydrophobic. In addition to being an innocuous and tasteless polymeric material, PVB can endure low temperatures, light, changes in humidity, bacteria, microorganisms, alkali and diluent acid. ${ }^{12}$ Moreover, it reveals some hydrophilicity because of its hydroxyl groups. Therefore, PVB is an attractive material for preparing porous materials, although there are very few literature reports on the preparation of PVB porous materials using the TIPS process. ${ }^{13}$ Therefore, investigating the preparation of PVB porous materials is a very important topic, especially because materials with high porosity are used in culturing organisms during sewage treatment processes.

During the preparation of PVB porous materials via the TIPS process, the diluent plays an essential role in influencing the ultimate morphologies and performance of the PVB porous materials. Various diluents have good compatibility with PVB at high temperature; however, most of them are non-water soluble and some are even known to be explosive, decreasing the impact of the porous material for environmental protection. Thus, using an environmentally friendly diluent is of great importance in preparing porous materials. In fact, it should be noted that very little optimisation work has been carried out on the diluents used in synthesizing PVB porous materials via the TIPS process. On the basis of their excellent miscibility with PVB, low volatility, relatively low molecular weights, environmental friendliness and good thermal stability at high temperatures, PEG-containing plasticizers have been used as diluents to 
prepare PVB hollow fiber membranes by the TIPS method. ${ }^{\mathbf{1 4 - 1 7}}$ Due to the superior performance of the hollow fiber membranes, it is possible to prepare PVB materials with welldeveloped pore structures, surface areas, adsorption, high strength and elongation of breakage, and chemical stability via TIPS.

The objective of the present study is to investigate the effects of the preparation conditions in the preparation of a biconnected structure PVB porous heddle by the TIPS process. The phase diagram of the PVB-PEG400 system as a function of the polymorphisms, morphology, and properties of the PVB porous heddle is presented as well.

\section{Experimental procedure}

\subsection{Materials}

The copolymer poly(vinyl butyral) (PVB) with a viscosity of 5 cps (apply 1 cup) was purchased from Guangdong Yuemei Chemical Co., Ltd. The vinyl butyral and vinyl alcohol parts of the copolymer are 80 and 18 weight percent (wt\%), respectively; the residual vinyl acetate part is $2 \mathrm{wt} \%$. Polyethylene glycol (PEG, $M_{\mathrm{w}}=400$, hereinafter referred to as PEG400), used as the diluent, was purchased from Aladdin. All chemicals were used without further purification.

\subsection{Phase diagrams}

Appropriate amounts of PVB and PEG400 were weighed into a glass test tube, and the blend was heated and shaken in an oil bath at $170{ }^{\circ} \mathrm{C}$, mixing for $30 \mathrm{~min}$ in a nitrogen atmosphere, in order to prepare a homogenous solution. Solid PVB-PEG400 samples were produced after the blend solutions were cooled under liquid nitrogen.

In the PVB-PEG400 system, studying the melting point $\left(T_{\mathrm{m}}\right)$ is of great importance for determining a suitable temperature to obtain a homogenous PVB-PEG400 system. Also, the glass transition temperature $\left(T_{\mathrm{g}}\right)$ is key to terminate coarsening. The $T_{\mathrm{m}}$ and $T_{\mathrm{g}}$ curves were determined photometrically using a Q2000 differential scanning calorimeter (DSC, Zhejiang Zhongda Technical Import Co, Ltd). Samples of PVB powder and different concentrations of solid PVB-PEG400 were used, and the measurements were performed by heating from $30^{\circ} \mathrm{C}$ to $175{ }^{\circ} \mathrm{C}$ under an inert nitrogen atmosphere at a flow rate of 50 $\mathrm{ml} \mathrm{min}^{-1}$. After waiting for $3 \mathrm{~min}$ to ensure complete melting and equilibration, the samples were cooled to room temperature at a rate of $10{ }^{\circ} \mathrm{C} \mathrm{min}^{-1}$.

The cloud point ( $\left.T_{\text {cloud }}\right)$ is the temperature of the polymer separate diluent, which is very important in addition to the phase separation mechanism. A small amount of prepared solid sample was heated on the THMS-600 hot stage of a LEICA DMLP TL\&RT thermo-optical microscope (Linkam UK/leica Germany) to $170{ }^{\circ} \mathrm{C}$ for $3 \mathrm{~min}$ and then cooled to $30{ }^{\circ} \mathrm{C}$ at a rate of $3{ }^{\circ} \mathrm{C} \min ^{-1}$. $T_{\text {cloud }}$ was determined by monitoring the appearance of turbidity under an optical microscope. The average values were determined by measuring at least five times.

\subsection{Preparation of PVB porous heddles}

PVB porous heddles were prepared using laboratory selfassembly equipment (XNR-400A melt flow indexer, Shanghai Hesheng Instruments Technology Co. Ltd) with the following procedures (Fig. 1). PVB-PEG400 blending samples were fed into the heater, heated to respective temperatures of $150{ }^{\circ} \mathrm{C}$, $160{ }^{\circ} \mathrm{C}$, or $170{ }^{\circ} \mathrm{C}$, and thermally insulated for a period of time. Short thermal insulation was employed in the sealed furnace chamber to ensure complete and even mixing. After holding at this high temperature for $10 \mathrm{~min}$, the homogeneous polymer solution was fed to a spinneret under a peristaltic pump. The pressure over the polymer solution was in the range of 0.0325 to $0.04 \mathrm{MPa}$; to obtain the same extrusion rate, a higher pressure was needed for the greater molecular weight of PEG and the higher concentration of PVB due to their greater viscosity. The diameter of the spinneret was $1.6 \mathrm{~mm}$. Then, the blending solution was extracted to acquire the nascent heddle after immersion in a water bath at $0{ }^{\circ} \mathrm{C}, 30{ }^{\circ} \mathrm{C}$, or $40{ }^{\circ} \mathrm{C}$ at an air gap distance of zero and was finally wound by a take-up winder.

The PVB heddles were extruded from the spinneret and wound on a take-up winder after being placed in water baths at different temperatures to induce phase separation and solidify the porous heddles. The variables in the spinning process were PVB concentration, extrusion temperature, quenching temperature, and take-up speed. The air gap distance of the process was zero. The diluent remaining in each heddle was extracted by immersing it in water for $24 \mathrm{~h}$ and freeze-drying for $48 \mathrm{~h}$. In the end, the PVB-PEG400 microporous heddles were obtained.

2.3.1 Morphology studies. The dry PVB porous heddles were fractured in liquid nitrogen and deposited on copper holders. All samples were coated with gold in vacuo. The morphologies of the membranes were examined by scanning electron microscopy (ultra 55).

2.3.2 Porosity. The PVB porous heddles were immersed in deionized water for $48 \mathrm{~h}$ to become wet after measuring the dry

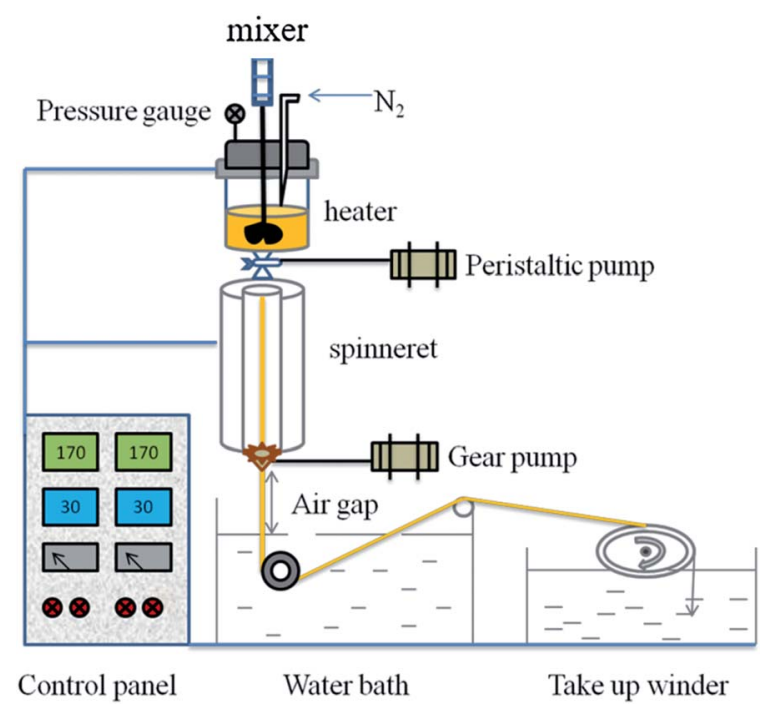

Fig. 1 Schematic of the thermally induced phase separation (TIPS) process. 
weights of the heddles; the wet weights were then measured. The overall porosities of the PVB porous heddles were calculated according to the following correlation (1):

$$
\varepsilon=\frac{\left(m_{\mathrm{w}}-m_{\mathrm{d}}\right) / \rho_{\mathrm{w}}}{\frac{m_{\mathrm{w}}-m_{\mathrm{d}}}{\rho_{\mathrm{w}}}+m_{\mathrm{d}} / \rho_{\mathrm{p}}} \times 100 \mathrm{wt}^{\circ} \%
$$

where $m_{\mathrm{w}}$ and $m_{\mathrm{d}}$ are the weights of the wet and dry heddles, respectively, and $\rho_{\mathrm{w}}$ and $\rho_{\mathrm{p}}$ are the water density $\left(1.0 \mathrm{~g} \mathrm{~cm}^{-3}\right)$ and polymer density $\left(1.07 \mathrm{~g} \mathrm{~cm}^{-3}\right)$, respectively. At least five samples were used for measuring the porosities; finally, the average values were reported. The standard deviation from the mean value is $5 \%$.

2.3.3 Mechanical properties. The tensile strengths and elongations of the PVB porous heddles were measured by an Instron testing machine (Instron 3369). The heddle was fastened vertically in the holding device with a length of $20 \mathrm{~mm}$. Then, the heddle was extended at a constant elongation rate of $50 \mathrm{~mm} \mathrm{~min}^{-1}$ until it broke. The tensile strength was calculated on the basis of the cross-sectional area of the porous heddle. The tensile strengths and elongations are the average of at least three heddles for each type.

2.3.4 Crystallinity. Wide angle X-ray diffraction data were recorded on a Fixed Slits detector with a power of $2 \mathrm{~kW}$ and Nifiltered $\mathrm{Cu} \mathrm{K} \alpha$ radiation. The detected area was 400 to $520 \mathrm{~mm}$, and the exposure time was $400 \mathrm{~s}$; the angle $(2 \theta)$ was shifted from $5^{\circ}$ to $70^{\circ}$. All presented XRD data in the study were calculated by Jade software with an error of fitting $(R \%)$ of about $5 \%$. We conducted at least three individual analyses in order to achieve reliability.

\section{Results and discussion}

\subsection{Phase diagrams}

Fig. 2 shows the phase diagram of the PVB-PEG400 system, including the $T_{\mathrm{m}}, T_{\mathrm{g}}$ and $T_{\text {cloud }}$ of PVB-PEG400. There is a vital gap between phase differences, demonstrating that the morphology of the heddle transitions is a function of PVB

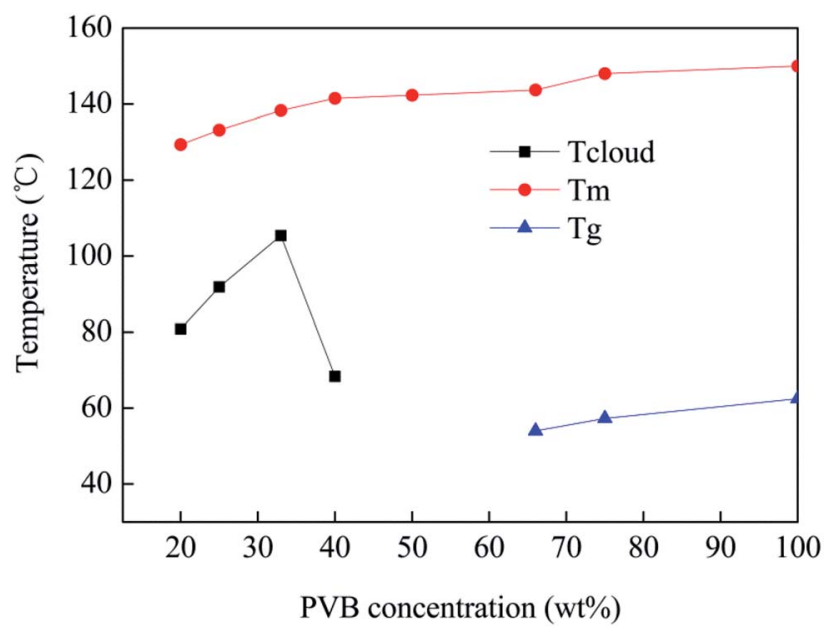

Fig. 2 Phase diagram of PVB-PEG400. concentration, whereas the $T_{\mathrm{m}}$ clarifies the suitable temperature for a homogenous solution.

The $T_{\mathrm{m}}$ curve is above the $T_{\text {cloud }}$ curve, which indicates that in the process of L-L phase separation, the local PVB concentration of polymer-rich phase must have been greater than the critical concentration to offer enough time for droplet formation. In the PVB-PEG400 system, with increasing concentration of PVB, not only did the $T_{\mathrm{g}}$ dramatically increase, but the $T_{\text {cloud }}$ also gradually increased initially and then decreased. As can be seen in Fig. 2, the $T_{\text {cloud }}$ increases in the range from $68{ }^{\circ} \mathrm{C}$ to $105{ }^{\circ} \mathrm{C}$ and the $T_{\mathrm{g}}$ decreases from $62{ }^{\circ} \mathrm{C}$ to $54{ }^{\circ} \mathrm{C}$. The influence of PEG400 on the $T_{\mathrm{g}}$ cannot be neglected for the interaction of the blend. This can mainly be attributed to the synergistic effect of the compatibility and agglomeration of PEG400. ${ }^{15,16}$ Better compatibility is obtained and ensembles form because the aggregation of excess PEG400 surpasses the solidification of the PVB. Therefore, the $T_{\mathrm{g}}$ decreases with increasing PEG content. When the PEG400 content is less than $66 \mathrm{wt} \%$, PVB is inclined to solidify due to the poor compatibility between PVB and PEG400; thus, $T_{\mathrm{g}}$ increases.

Also, with increasing PVB concentration, the phase separation is more inclined to occur at a higher temperature in the binary PVB-PEG400 system. Because the viscosity of the blend solution increases, a three-dimensional network structure forms between molecules, preventing movement of the molecular chains. Therefore, the PVB-PEG400 system requires more condenser depression to solidify with a high concentration of PVB. Meanwhile, phase inversion occurs with a PVB concentration of $33 \mathrm{wt} \%$. Generally, the L-L phase inversion mechanisms are nucleation and growth (NG) or spinodal decomposition (SD) when the cooling temperature reaches the binodal line L-L phase. ${ }^{18-20}$ NG occurs in the metastable region (i.e. between the binodal and spinodal lines in the phase diagram) while SD occurs in the unstable region (under the spinodal line in the phase diagram). ${ }^{19}$ Depending on the mechanism of phase inversion occurring during the heddle formation process, different morphologies can be obtained. It is difficult to form biconnected network structures due to the heterogeneous solution at high temperature when the concentration is above $33 \mathrm{wt} \%$.

\subsection{Morphology}

It is interesting to discover a process that induces biconnected structures with TIPS. During the preparation of PVB porous heddles using PEG400, a L-L phase separation mechanism leads to polymer-rich and polymer-lean phases, respectively, resulting in PVB porous heddles with biconnected structures. Because the blend solution can be brought into different regions in the phase diagram by varying the composition and cooling rate, the morphology of a PVB porous heddle is directed significantly by the PVB concentration, quenching temperature and extrusion temperature.

\subsection{PVB porous heddles}

As can be seen in the SEM images, most of the heddles had biconnected structures. The biconnected structure morphology 
is the typical structure of $\mathrm{L}-\mathrm{L}$ phase separation via binodal separation. However, the pore size changes from the inner part to the surface. Particularly, because the surface structures of the porous heddles are in direct contract with the water in the coagulation bath, the pore sizes of the droplets are small due to the higher cooling rate compared with the inner lumen part, which is still in contact with the melt blending solution after spinning.

3.3.1 Effects of PVB concentration. Polymer concentration plays an important role in TIPS and polymer solidification. In this section, accompanied by heat transfer at the blend polymer solution-coagulation bath interface, the effects of the PVB concentration are reported. Four weight concentrations were adopted, namely 20, 25, 33, and $40 \mathrm{wt} \%$, for the PVB-PEG400 system.

Fig. 3 shows the three-dimensional morphologies at a quenching temperature of $0{ }^{\circ} \mathrm{C}$. Fig. 3(a1-d1) and (a2-d2) show the cross sections and top surface morphologies of the PVB porous heddles. The pore size of the heddles shows
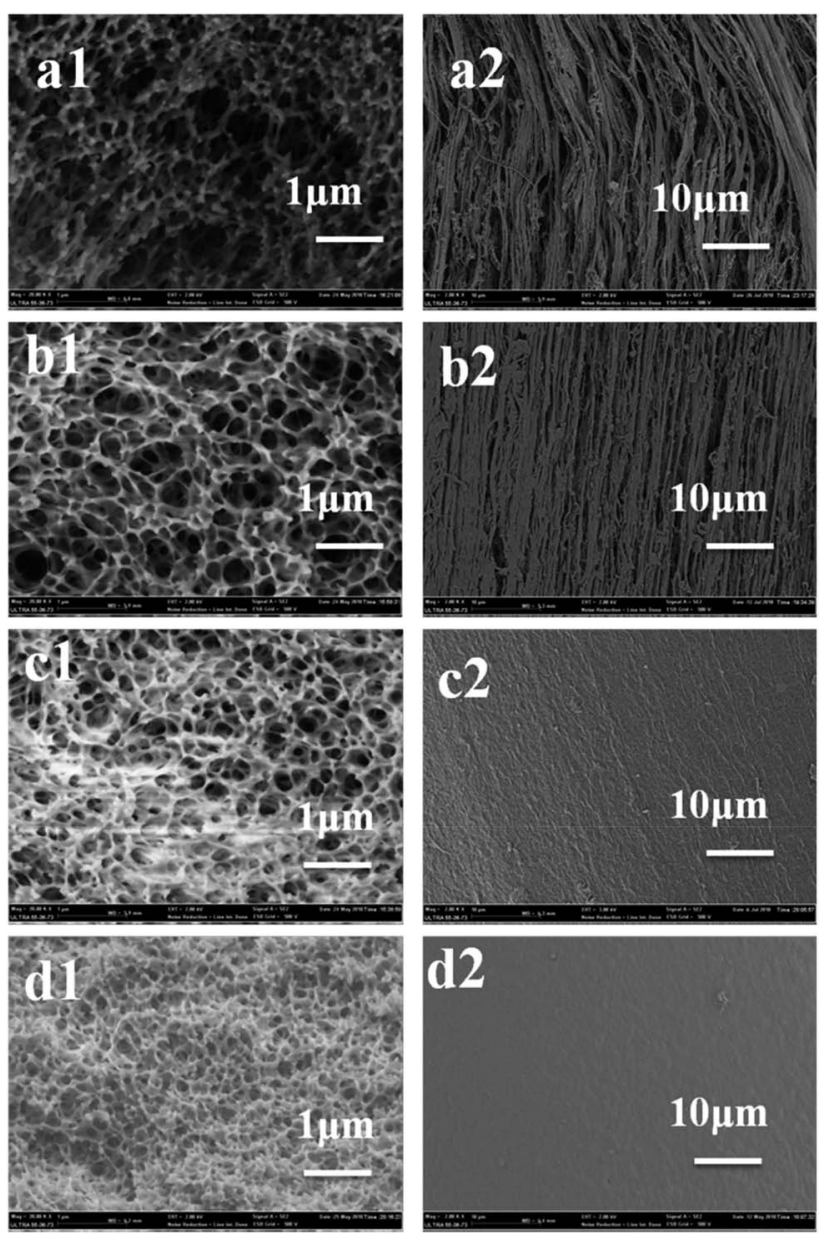

Fig. 3 SEM morphologies of PVB porous heddles with an extrusion temperature of $170^{\circ} \mathrm{C}$, quenching temperature of $0^{\circ} \mathrm{C}$, take-up speed of $0.143 \mathrm{~m} \mathrm{~s}^{-1}$, air distance of zero and different PVB concentrations. (a), (b), (c), and (d) are the PVB porous heddles prepared with PVB concentrations of $20,25,33$, and 40 wt\%, respectively; (1) and (2) are the cross sections and top surfaces, respectively. a decreasing tendency with increasing PVB concentration. As shown in Fig. 3(a1-d1), the PVB heddle shows a more biconnected structure at a low concentration due to the poorer compatibility between PVB and PEG400; meanwhile, the structure of the PVB heddles transforms from a honeycomb structure to a non-penetrating structure with a PVB concentration of $40 \mathrm{wt} \%$. It can be seen that the pore size at a PVB concentration of $33 \mathrm{wt} \%$ is smaller than that at $20 \mathrm{wt} \%$. In fact, this phenomenon, which depends on the preexistence of the phase diagram and viscosity in the blend solution, ${ }^{15,16}$ is directly proportional to PVB concentration in the PVB-PEG400 system. According to the phase diagram in Fig. 2, $33 \mathrm{wt} \%$ is the concentration of the phase inversion point; this indicates that a non-penetrating structure followed by a biconnected structure will be thermally induced as the temperature decreases when the PVB concentration is higher than $33 \mathrm{wt} \%$, while only a honeycomb structure will be obtained as the temperature decreases when the PVB concentration is lower than $33 \mathrm{wt} \%$. The PEG400-rich phase needs more time to coarsen due to the fact that the gap between $T_{\text {cloud }}$ and $T_{\mathrm{g}}$ increases with increasing PVB concentration in the range of $20 \mathrm{wt} \%$ to $33 \mathrm{wt} \%$ in Fig. 2 . In addition, it is difficult to instantly form larger droplets with greater viscosity at a higher concentration. On the basis of the above two reasons, discontinuous structures occur in the TIPS process at a PVB concentration of $40 \mathrm{wt} \%$. As can be seen in Fig. 3(a2-d2), the pore size decreases as the PVB concentration increases due to the smaller chance of forming large droplets under constant supercooling temperature at a higher PVB concentration. Furthermore, the number of pores decreases with increasing PVB concentration due to a sudden exchange of PEG400-water and L-L separation. During the TIPS process (Fig. 1), the PVB dissolves in the diluent at high temperature, and a homogenous melting blend is formed. Once the blend solution enters the water, the PVB-rich phase gathers on the surface of the heddle and the PEG400-rich phase becomes porous, leading to greater enhancement of the PVB concentration and a denser top surface morphology with increasing PVB concentration. $^{21,22}$

3.3.2 Effects of extrusion temperature and quenching temperature. L-L TIPS occurs and PVB400-rich droplets begin to form and grow when the PVB-PEG400 blending solution enters the quenching water. When the PVB-PEG400 is solidified with a faster cooling rate, the final PVB porous heddle is formed from the PVB substrate and the pores are full of PEG400. Hence, the size is closely related to the final pore size. Namely, a larger droplet size results in a larger pore size. ${ }^{23}$ The cooling rate is directly related to the extrusion temperature and quenching temperature in the TIPS process. Fig. 4 shows SEM morphologies of the cross sections of PVB porous heddles prepared at three different extrusion temperatures $\left(150{ }^{\circ} \mathrm{C}, 160^{\circ} \mathrm{C}\right.$ and 170 $\left.{ }^{\circ} \mathrm{C}\right)$ and three different quenching temperatures $\left(0{ }^{\circ} \mathrm{C}, 30^{\circ} \mathrm{C}\right.$ and $40{ }^{\circ} \mathrm{C}$ ). The pore size in the cross section of the heddle increases with increasing extrusion temperature, as seen from the biconnected structures (Fig. $4 \mathrm{a}-\mathrm{c}$ ). Because the void volumes increase in systems with higher extrusion temperatures because of increased movement of the copolymer segments, the heddle pore size increases (Fig. 4b). As can be seen in Fig. 5, the pore 


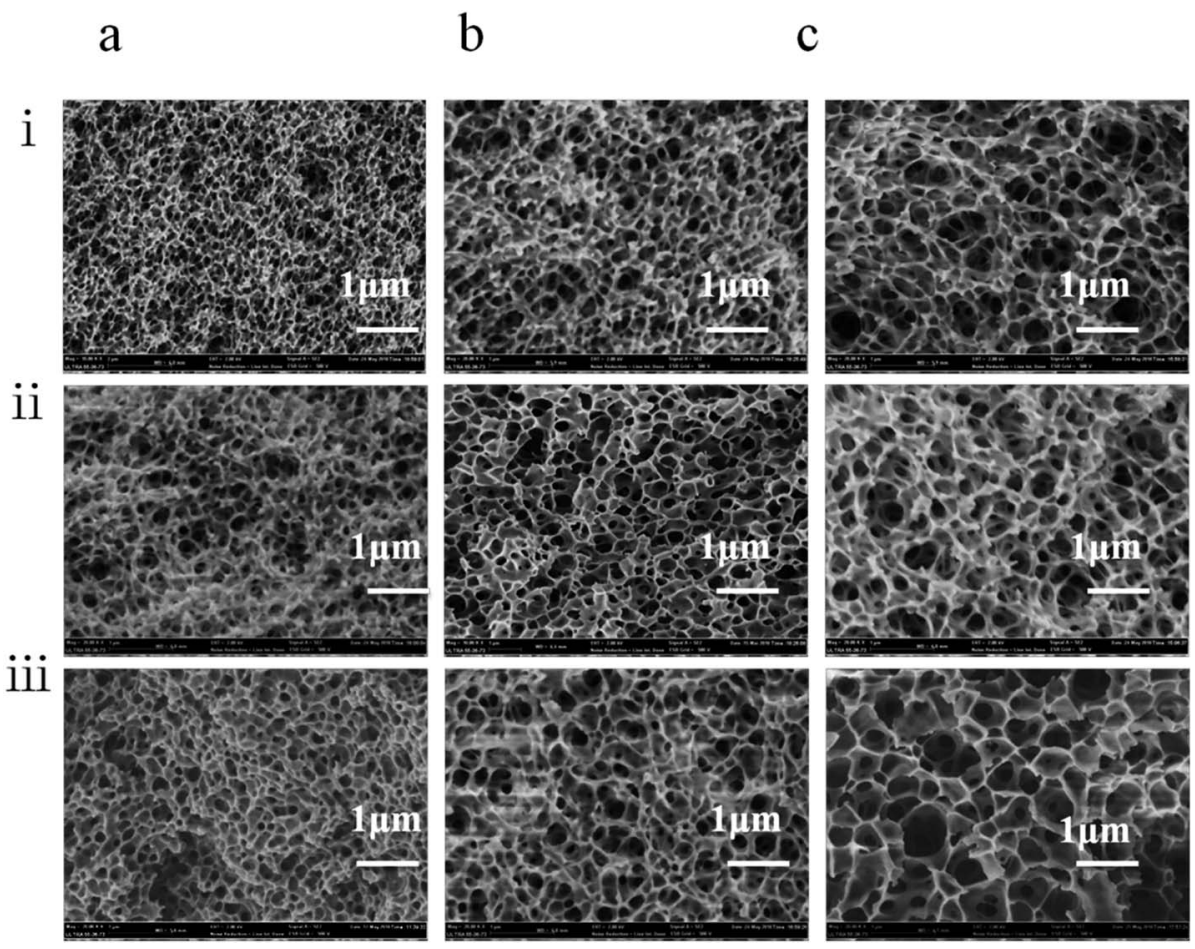

Fig. 4 SEM morphologies of cross sectional PVB porous heddles with a PVB concentration of 25 wt\%, take-up speed of $0.143 \mathrm{~m} \mathrm{~s}^{-1}$, air distance of zero, different extrusion temperatures and different quenching temperatures. (a), (b) and (c) are the PVB porous heddles prepared with different extrusion temperatures of $150^{\circ} \mathrm{C}, 160^{\circ} \mathrm{C}$, and $170^{\circ} \mathrm{C}$, respectively; (i), (ii) and (iii) are the PVB porous heddles prepared with different quenching temperatures of $0{ }^{\circ} \mathrm{C}, 30^{\circ} \mathrm{C}$, and $40{ }^{\circ} \mathrm{C}$.

a

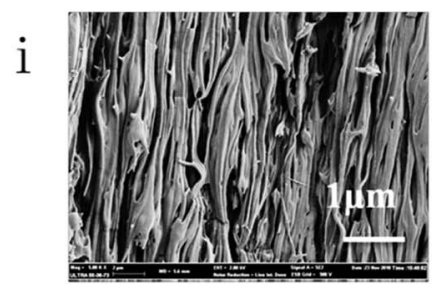

ii

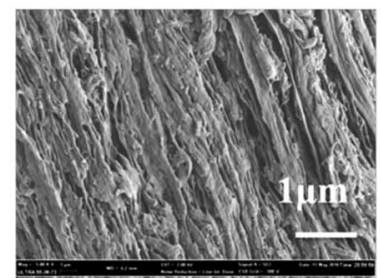

iii

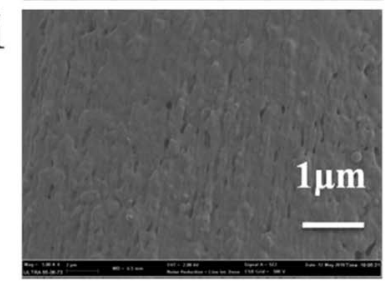

b
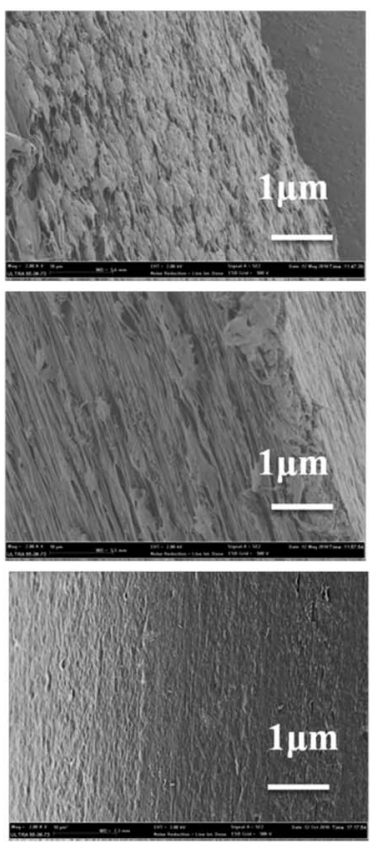

C
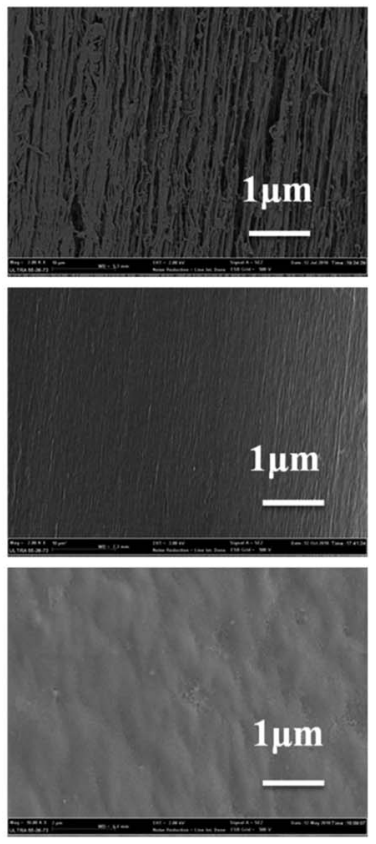

Fig. 5 SEM morphologies of the surfaces of PVB porous heddles with a PVB concentration of $25 \mathrm{wt} \%$, take-up speed of $0.143 \mathrm{~m} \mathrm{~s}^{-1}$, air distance of zero, different extrusion temperatures and different quenching temperatures. (a), (b) and (c) are the PVB porous heddles prepared with different extrusion temperatures of $150^{\circ} \mathrm{C}, 160^{\circ} \mathrm{C}$, and $170{ }^{\circ} \mathrm{C}$, respectively; (i), (ii) and (iii) are the PVB porous heddles prepared with different quenching temperatures of $0^{\circ} \mathrm{C}, 30^{\circ} \mathrm{C}$, and $40^{\circ} \mathrm{C}$. 
size on the surface of the heddle decreases with increasing extrusion temperature, accompanied by a narrower pore size distribution from the interior to the external surface. This is because the droplet size increases with decreasing viscosity of the blend solution; ${ }^{24}$ namely, the droplet is regulated by the extrusion temperature, resulting in a smooth flow of PVB and forming a rough surface with a uniform, narrow distribution of pores. Fabrication of porous heddles at temperatures higher than $170{ }^{\circ} \mathrm{C}$ is not possible due to the low polymer viscosity at high extrusion temperatures.

The blend polymer solution-coagulation bath interface is of great importance for determining the final heddle morphology, and the quenching temperature controls the heddle structure dramatically. We observed that the pore size decreased with increasing quenching temperature (Fig. 4). On the one hand, this results from the fact that the transfer is enhanced with increasing quenching temperature. Furthermore, the PEG400 moves to the heddle surface from the substrate, ${ }^{25}$ which consequently increases the polymer concentration and decreases the heddle pore size in the cross section. On the other hand, the growth process of the droplet shortens at higher quenching temperatures; therefore, a smaller pore size is obtained at a faster cooling rate. ${ }^{26}$
Surface SEM images of the heddle samples prepared at different quenching temperatures are shown in Fig. 5. With increasing quenching temperature, the pore sizes in the heddle surfaces increase, the number of pores decreases slightly, and the shapes of the pores become more regular. Because the mass transmission rate in $40^{\circ} \mathrm{C}$ quenching water is faster than in $0{ }^{\circ} \mathrm{C}$ water, the cooling rate of the PVB-PEG400 blending solution increases with decreasing quenching temperature; also, the PVB macromolecular chains have little time for arrangement, ${ }^{27,28}$ which decreases the pore sizes of the biconnected structures and increases the number of micropores to form heddles with biconnected structures. The driving force of $\mathrm{L}-\mathrm{L}$ phase separation decreases as the gap between the $T_{\mathrm{m}}$ of the PVB-PEG400 blending solution and the quenching temperature decreases. ${ }^{29}$ That is to say, the magnitude of this driving force is positively relatived to the supercooling degree. Generally, L-L phase separation and the solidification of the PVB-rich phase are the two competitive factors affecting the coarsening process, thus generating heddle morphologies. When the coarsening temperature falls between the binodal decomposition and spinodal decomposition regions, and when the supercooling degree is increased by the decreased quenching temperature, a faster solidification rate of PVB-rich phase leaves a shorter
A

B

C
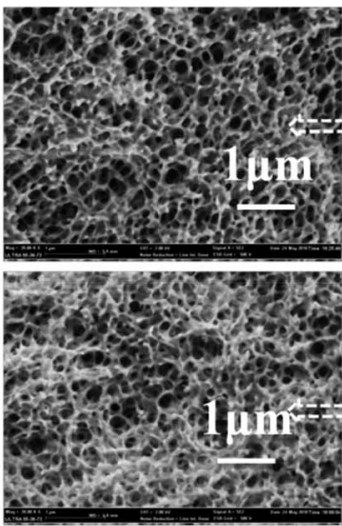

CS

TS
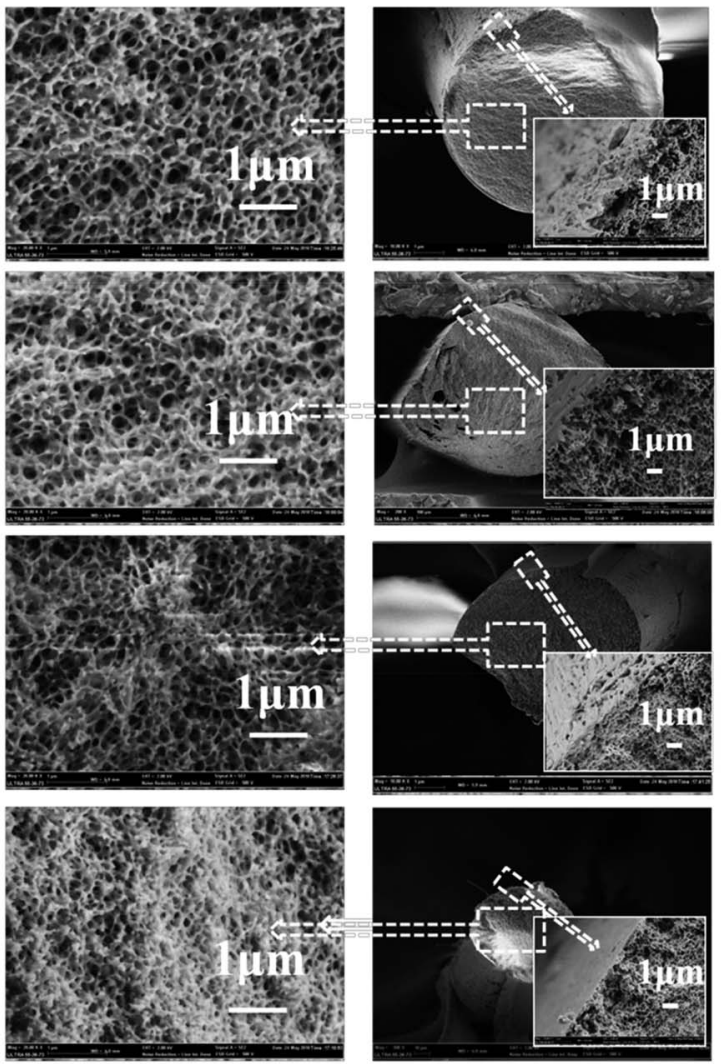
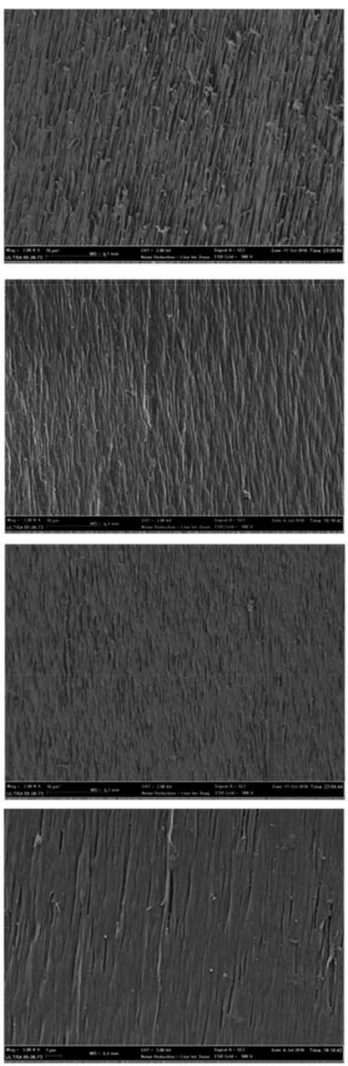

Fig. 6 SEM morphologies of PVB porous heddles with a PVB concentration of $25 \mathrm{wt} \%$, air distance of zero, extrusion temperature of $170{ }^{\circ} \mathrm{C}$, quenching temperature of $0^{\circ} \mathrm{C}$ and different take-up speeds. (A), (B), (C), and (D) are the PVB porous heddles prepared with different take-up speeds of $0.164,0.218,0.245$, and $0.272 \mathrm{~m} \mathrm{~s}^{-1}$, respectively; (CS) and (TS) are the cross sections and top surfaces, respectively. 
time for the PEG-lean phase to grow; this results in small pore sizes, as shown on the heddle surfaces (Fig. 5). ${ }^{30,31}$ Namely, when the quenching temperature decreases, the size of the droplets decreases due to the fact that slower cooling rates give the polymer chains much less opportunity to disentangle during glass transition. In contrast, larger pore sizes are formed with longer coarsening times.

The changes in the PVB porous heddle biconnected structures and the pore sizes are affected by the extrusion temperature and quenching temperature. In essence, the changes are influenced by the synergistic effects of the PVB concentration and cooling rate.

3.3.3 Effects of take-up speed. The effects of take-up speed on the cross sections of the PVB porous heddles are shown in Fig. 6 . The diameters are determined by the take-up speed and the extruding rate of the PVB-PEG400 blend solution. The drawing ratio of the porous heddle increases as the take-up speed increases. It can be seen that the diameters of the heddles decrease with increasing take-up speed (Fig. 6, CS).

When the take-up speed is lower than $0.218 \mathrm{~m} \mathrm{~s}^{-1}$, the crosssectional morphologies remain similar (Fig. 6, CS). All the samples present biconnected structures; furthermore, the pore size gradually decreases from the interior to the surface, which is an asymmetric structure in the porous heddles. The compact structure arises from the different cooling rates during the L-L phase separation. The cooling rate of the PVB-PEG400 blending solution in the centre is much lower due to the obstruction of the hot PVB-PEG400 blending structure..$^{32}$ However, when the take-up speed reaches $0.245 \mathrm{~m} \mathrm{~s}^{-1}$, the asymmetric structure disappears. Instead, the whole cross section manifests a more homogeneous structure, and the pore size of the heddle decreases. Those changes are closely related to two factors. First of all, the cooling rate is essential for the heddle morphology structures., ${ }^{9,2933}$ When the take-up speed increases, the diameter of the heddle decreases and the cooling rate increases due to the constant extrusion temperature and quenching temperature. ${ }^{29}$ The second reason is that the shear force of the blend solution in the spinneret changes with changes in the take-up speed during the spinning process. ${ }^{34,35}$ Similarly, the take-up speed plays a vital role in the PVB macromolecular state before solidification and then directs the structure, properties, and dimensions of the PVB porous heddle in the TIPS process. Furthermore, there is no obvious difference in the surface structures with different take-up speeds, as shown in Fig. 6, TS; also, the heddles display narrow, uniform porous structures. This illustrates that the effects of the take-up speed on the surface structures are very slight.

Furthermore, the diameters are determined by the take-up speed and the extruding rate of the PVB-PEG400 blend solution. The drawing ratio of the porous heddle increases as the take-up speed increases. It can be seen that the diameters of the heddles decrease with increasing take-up speed (Fig. 6, CS).

\subsection{Porosity and mechanical properties}

3.4.1 Effects of PVB concentration. The porosities and mechanical properties of the PVB porous heddles produced with different polymer concentrations are listed in Fig. 7. The porosity decreases from $74.63 \%$ to $37.03 \%$ as the PVB concentration increases due to the fact that the probability of the PEG400-lean phase decreases during phase separation, which is supported by the SEM images (Fig. 3). The porosity of the prepared PVB porous heddles reaches $74.63 \%$ and the mechanical strength is $10.43 \mathrm{MPa}$ when the PVB concentration is $20 \mathrm{wt} \%$. The breakage strength increases from $10.4 \mathrm{MPa}$ to 28.68 MPa with increasing PVB concentration; also, the rate of increase is enhanced significantly when the PVB concentration is higher than $33 \mathrm{wt} \%$. In the process of heddle preparation, the polymer concentration and the cooling rate determine the morphology and breakage strength of the heddle. The diluentlean phase became pores upon extraction in water. Hence, porous heddles with higher strength and elongation of breakage are obtained due to the increased integrity, given that a higher PVB concentration generates higher macromolecule entanglement. Overall, the mechanical properties are negatively related to the porosity as the PVB concentration increases. This result indicates good agreement between the observed and calculated intensities in porous materials obtained using pure polymers by TIPS processing; similar trends for the porosities and mechanical properties of porous materials were found with a

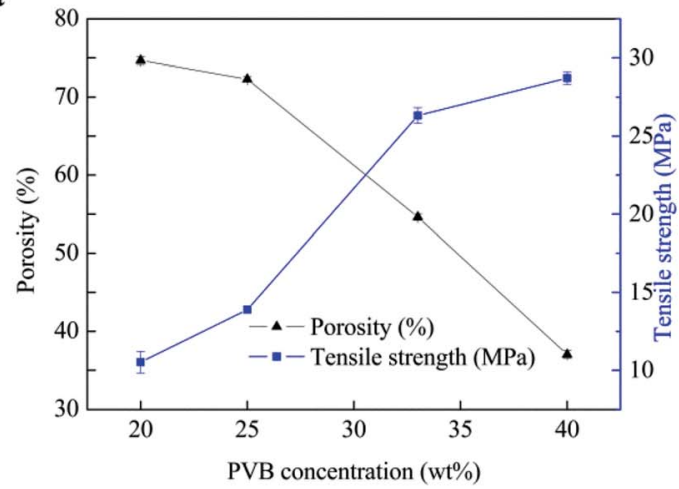

$\mathrm{b}$

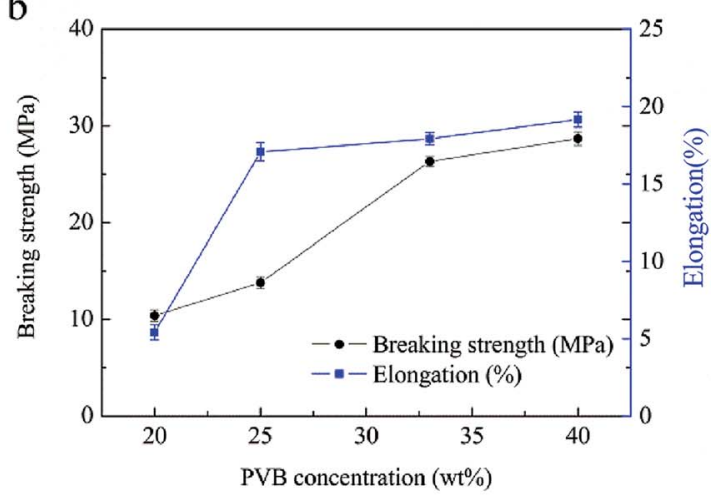

Fig. 7 Porosities (a) and mechanical properties (b) of PVB porous heddles produced with different polymer concentrations. 
increasing polymer concentration under given experimental conditions. $^{36,37}$

3.4.2 Effects of extrusion temperature and quenching temperature. Fig. 8 shows the effects of extrusion temperature and quenching temperature on the porosity and tensile strength of PVB porous heddles. As shown in Fig. 4, the porosity increases from $24.3 \%$ to $72.3 \%$ with increasing extrusion temperature. The droplet size increases with increasing PVB extrusion temperature because of the increase of the void volumes in the PVB-PEG400 blend solution inside the heddle. ${ }^{38}$ Overall, the tensile strength, porosity and pore size of the heddles increased with increasing extrusion temperature (Fig. 8a), and the tensile strengths were in the range of 45 to $49 \mathrm{MPa}$. This is due to the fact that the skin layer close to the surface is prepared with a small, narrow size (Fig. 5), and the effects of high extrusion temperature result in a much higher
PVB concentration of the layer at the heddle surface. ${ }^{39}$ Compared with the internal microporous structure, the dense skin layer of the outer surface plays a major role in enhancing the tensile strength.

The porosity decreases with increasing quenching temperature (Fig. 8b), which is in good agreement with the observed photosynthetic activity in the SEM morphologies (Fig. 4). This is due to the fact that larger pore sizes are induced on the surfaces of the heddles prepared at relatively higher quenching temperatures (Fig. 5). In addition, the tensile strength decreases with increasing quenching temperature due to the synergy effect between the uniform porous inner substrate and the uneven surface. ${ }^{32}$ In a word, the microstructure immediately influences the mechanical properties.

3.4.3 Effects of take-up speed. The effects of take-up speed on the porosity, crystallinity and mechanical properties of the
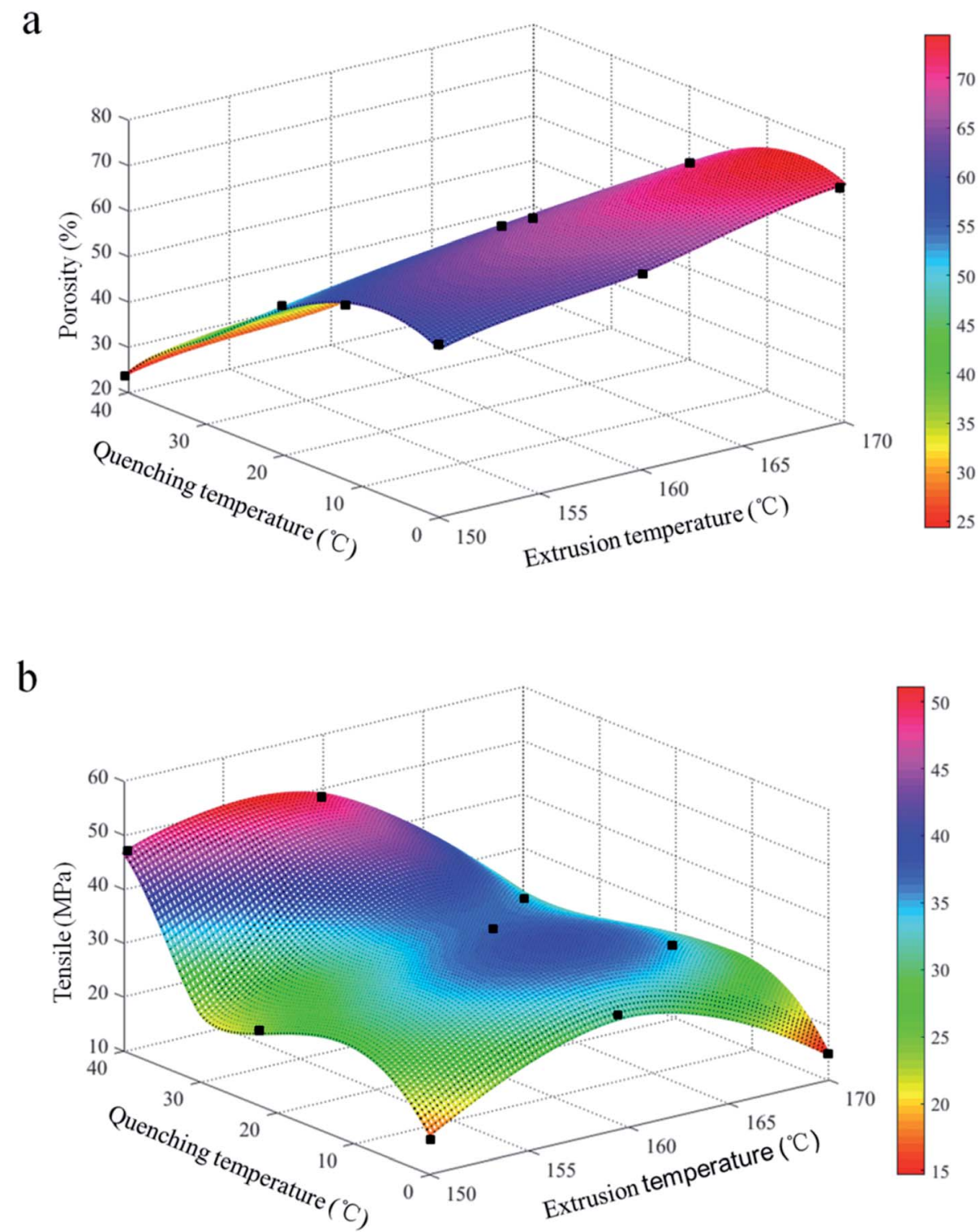

Fig. 8 Porosities (a) and mechanical properties (b) of PVB porous heddles produced with different extrusion temperatures and quenching temperatures. 
a

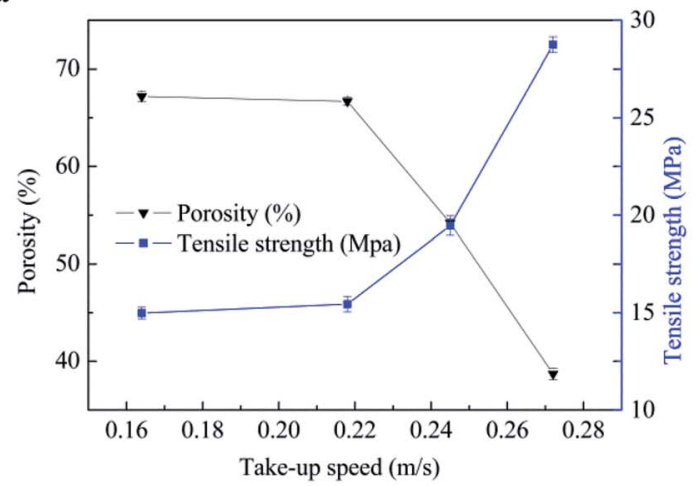

C

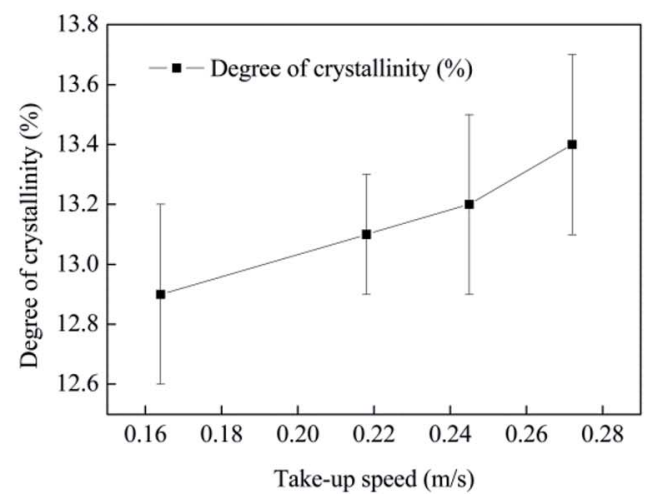

b

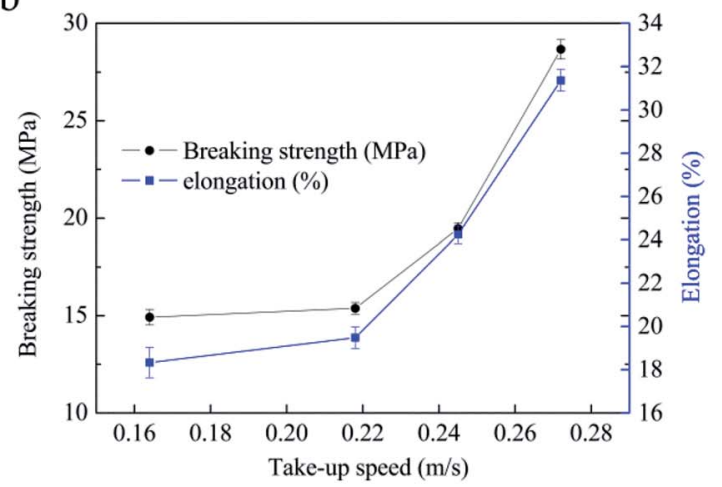

Fig. 9 Porosities (a), mechanical properties (b) and degrees of crystallinity (c) of PVB porous heddles produced with different take-up speeds.

PVB porous heddles are summarized in Fig. 9. The porosity decreases from $67.2 \%$ to $38.7 \%$ with increasing take-up speed (Fig. 9a). Furthermore, it is important to highlight that the porosity decreases mildly when the take-up speed rises to $0.218 \mathrm{~m} \mathrm{~s}^{-1}$, which is consistent with the SEM observations (Fig. 6). Both the strength and elongation of breakage increase significantly, from about $15 \mathrm{MPa}$ to $29 \mathrm{MPa}$, with increasing take-up speed, as shown in Fig. 9b. The mechanical properties are closely related to the aggregation structures and microstructures of the PVB porous heddles, which is verified by the proportional cooling rate. Generally, a high take-up speed produces a higher elongation stress, which is beneficial to the orientation of the PVB macromolecular chains; meanwhile, a high cooling rate results in more imperfect aggregation structures. ${ }^{35}$ In this study, the take-up speed was very low compared with the take-up speeds in the chemical fiber industry. Hence, the influence of elongation stress on the aggregation structures is very small compared to that of the cooling rate..$^{34,40}$ Namely, the aggregation structure is mainly constrained by the cooling rate. Also, this is supported by the fact that the crystallinity of the porous heddles changes inconspicuously with increasing take-up speed (Fig. 9c). Good connection of aggregations without obvious orientation leads to higher strength and elongation of breakage. ${ }^{41}$ Therefore, increase of the take-up speed in the experimental range will be favorable to the enhancement of the strength.

\section{Conclusion}

In this paper, PEG400 was used as an environmentally friendly diluent for PVB porous heddle preparation via the TIPS process. The effects of polymer concentration, extrusion temperature, quenching temperature and take-up speed on the morphologies and properties of the PVB porous heddles were investigated.

L-L phase separation occurred under the preparation conditions in this study independent of the PVB concentration and cooling rate. Biconnected structures were prepared during PVB porous heddle preparation. There is more time for droplet growth at a lower cooling rate, resulting in a lower PVB concentration and larger pore sizes. The pore size and porosity decrease and the mechanical properties increase with increasing PVB concentration. In addition, the pore sizes and porosities of the heddles increase when the extrusion temperature increases from $150{ }^{\circ} \mathrm{C}$ to $170{ }^{\circ} \mathrm{C}$. By increasing the quenching temperature during the TIPS process, the pore size and mechanical properties decrease while the porosity increases. This indicates that the mechanical properties are negatively related to the porosity with increasing PVB concentration in the TIPS process. The porosity of the prepared PVB porous heddles reached $74.63 \%$, and the mechanical strength was 10.43 MPa when the PVB concentration, the quenching temperature and the extrusion temperature were $20 \mathrm{wt} \%, 0{ }^{\circ} \mathrm{C}$ and $170{ }^{\circ} \mathrm{C}$, respectively. Based on our research, we conclude that the environmentally friendly diluent described here is 
competitive with PEG400 in preparing PVB porous heddles for porous carrier materials during water treatment applications.

\section{Conflicts of interest}

There are no conflicts to declare.

\section{Acknowledgements}

This work is supported by the National Natural Science Foundation of China (grant no. 21706238) and the Excellent Postgraduate Thesis Program of Zhejiang Sci-Tech University (Grant No. 2018 - XWLWPY-B-03-07, 2018 - XWLWPY-M-03-06).

\section{Notes and references}

1 E. Drioli, A. I. Stankiewicz and F. Macedonio, J. Membr. Sci., 2011, 380, 1-8.

2 A. Brunetti, A. Caravella, E. Drioli and G. Barbieri, Chem. Eng. Technol., 2012, 35, 1238-1248.

3 P. Bernardo and E. Drioli, Pet. Chem., 2010, 50, 271-282.

4 F. Liu, N. A. Hashim, Y. T. Liu, M. R. M. Abed and K. Li, J. Membr. Sci., 2011, 375, 1-27.

5 M. H. Gu, J. Zhang, X. L. Wang, H. J. Tao and L. T. Ge, Desalination, 2006, 192, 160-167.

6 J. A. Yang, X. L. Wang, Y. Tian, Y. K. Lin and F. Tian, J. Polym. Sci., Part B: Polym. Phys., 2010, 48, 2468-2475.

7 H. Sun, K. B. Rhee, T. Kitano and S. I. Mah, J. Appl. Polym. Sci., 2000, 75, 1235-1242.

8 X. Han, H. Ding, L. Wang and C. Xiao, J. Appl. Polym. Sci., 2008, 107, 2475-2479.

9 Y. K. Lin, G. Chen, J. Yang and X. L. Wang, Desalination, 2009, 236, 8-15.

10 S. Rajabzadeh, C. Liang and Y. Ohmukai, J. Membr. Sci., 2012, 423, 189-194.

11 F. Shen, X. Lu, X. Bian and L. Shi, J. Membr. Sci., 2005, 265, 74-84.

12 M. Gotoh, E. Tamiya and I. Karube, J. Appl. Polym. Sci., 1993, 48, 67-73.

13 X. Y. Fu, H. Matsuyama, M. Teramoto and H. Nagai, Sep. Purif. Technol., 2005, 45, 200-207.

14 X. Fu, H. Matsuyama, M. Teramoto and H. Nagai, Sep. Purif. Technol., 2006, 50, 363-371.

15 Y. R. Qiu, N. A. Rahman and H. Matsuyam, Sep. Purif. Technol., 2008, 61, 1-8.

16 Y. R. Qiu and H. Matsuyama, Desalination, 2010, 257, 117123.

17 Y. Qiu, J. Qi and Y. Wei, J. Cent. South Univ., 2014, 21, 21842190.
18 A. Bottino, G. Capannelli, S. Munari and A. Turturro, J. Polym. Sci., Part B: Polym. Phys., 1988, 26, 785-794.

19 D. R. Lloyd, S. S. Kim and K. E. Kinzerb, J. Membr. Sci., 1991, 64, 1-11.

20 M. Gu, J. Zhang, X. Wang, H. Tao and L. Ge, Desalination, 2006, 192, 160-167.

21 I. Pinnau and W. J. Koros, J. Polym. Sci., Part B: Polym. Phys., 1993, 31, 419-427.

22 M. H. V. Mulder, J. O. Hendrikman, J. G. Wijmans and C. A. Smolders, J. Appl. Polym. Sci., 1985, 30, 2805-2820.

23 L. U. Kim and C. K. Kim, J. Polym. Sci., Part B: Polym. Phys., 2006, 44, 2025-2034.

24 N. Ghasem, M. Al-Marzouqi and N. A. Rahim, Sep. Purif. Technol., 2012, 99, 91-103.

25 C. Zhang, Y. Bai, Y. Sun, J. Gu and Y. Xu, J. Membr. Sci., 2010, 36, 216-224.

26 F. Shi, J. Ma, P. Wang and Y. Ma, J. Taiwan Inst. Chem. Eng., 2012, 43, 980-988.

27 H. Matsuyama, Y. Takida, T. Maki and M. Teramoto, Polymer, 2002, 43, 5243-5248.

28 T. H. Xiao, P. Wang, X. Yang, X. H. Cai and J. Lu, J. Membr. Sci., 2015, 489, 160-174.

29 X. F. Li and X. L. Lu, J. Appl. Polym. Sci., 2006, 101, 29442952.

30 S. W. Song and J. M. Torkelson, J. Membr. Sci., 1995, 98, 209222.

31 X. F. Li, G. Q. Xu, X. L. Lu and C. F. Xiao, J. Appl. Polym. Sci., 2008, 107, 3630-3637.

32 S. Rajabzadeh, T. Maruyama, T. Sotani and H. Matsuyama, Sep. Purif. Technol., 2008, 63, 415-423.

33 X. L. Lu and X. F. Li, J. Appl. Polym. Sci., 2009, 114, 12131219.

34 G. Fortunato, A. G. Guex, A. M. Popa, R. M. Rossi and R. Hufenus, Polymer, 2014, 55, 3139-3148.

35 J. Yang, D. W. Li, Y. K. Lin, X. L. Wang, F. Tian and Z. Wang, J. Appl. Polym. Sci., 2008, 110, 341-347.

36 X. Wang, Z. Li, M. Zhang, T. Fan and B. Cheng, RSC Adv., 2017, 7, 10503-10516.

37 H. Zhang, Y. L. Zhao, H. T. Wang, W. Zhong, Q. G. Du and X. M. Zhu, J. Membr. Sci., 2010, 354, 101-107.

38 M. Shang, H. Matsuyama and M. Teramoto, Polymer, 2003, 44, 7441-7447.

39 D. R. Lloyd, K. E. Kinzer and H. S. Tseng, J. Membr. Sci., 1990, 52, 239-261.

40 C. Marega and A. Marigo, Eur. Polym. J., 2003, 39, 1713-1720. 41 X. Li, H. Liu and C. Xiao, J. Appl. Polym. Sci., 2013, 128, 10541060. 